\title{
trabalhonecessário
}

iss $\mathrm{n:} 1808-799 \mathrm{X}$

ano 1 - número 1 - 2003

\section{UNIVERSIDADE, PECADO NATIVO}

Maria Ciavatta[1]

Ninguém melhor que os artistas, os poetas, para intuir a verdade profunda dos acontecimentos. Assim é que entendo os versos de Belchior e Toquinho que ditos no contexto maior da repressão dos anos 70, aplicam-se ainda hoje à universidade como instância de criação de conhecimento e de libertação do ser humano das muitas prisões a que está sujeito: "porque o pecado nativo é simplesmente estar vivo, é querer respirar".[2] O movimento da história se realiza em um contexto de contradições engendradas pelo não conformismo a tudo que é articulado para aprisionar o espírito. Somente assim se pode entender as lutas pela existência das universidades públicas em nosso país.

A universidade brasileira é fruto tardio do colonialismo. Enquanto as mais antigas universidades européias são do século XII e, na América Latina, na República Dominicana, no México, no Peru, são do Século XVI, no Brasil, criou-se, na lei, a Universidade do Rio de Janeiro, pela agregação de três escolas existentes no Rio desde o século anterior, Direito, Medicina e Escola Politécnica. Apenas em 1931, com o Estatuto das Universidades Brasileiras, o governo implantou a Universidade criada, incorporando-Ihe outras escolas superiores. Esta veio a se tornar a Universidade do Brasil em 1937 e é a atual Universidade Federal do Rio de Janeiro.

Também a pós-graduação, como um sistema nacional. é tardia em nosso país, embora com algum avanço, em relação a outros países da América Latina. Fruto contraditório da ditadura que projetava um "Brasil grande", pelo pensamento crítico que gerou, o sistema de pós-graduação, nas diversas áreas do conhecimento, foi criado em 1971 e tem pouco mais de trinta anos. No México, foi criado em 1974 e, na maioria dos demais países latino-americanos, a pós-graduação é residual. Esta seria uma das razões para que o Brasil assumisse uma dívida histórica de oferecer oportunidades de qualificação neste nível para professores das diversas e conceituadas instituições latino-americanas. Mas parece que seria pedir demais a 
um país que trabalha em mão dupla, qualificando mestres e doutores e retirando-lhe o estímulo e as oportunidades de usar seu conhecimento a serviço do próprio país.

Quero destacar alguns aspectos desse processo perverso. Primeiro, como a pós-graduação é um processo histórico tardio e recente na vida universitária brasileira, três quartos $(74,7 \%)$ dos doutores de mais alto nível, segundo a classificação do CNPq, bolsistas de produtividade A1, categoria de pesquisador sênior, estão entre os 50 e os 69 anos.[3] O que evidencia que fizeram sua pós-graduação tardiamente para os padrões atuais em que os melhores alunos completam a graduação, o mestrado e o doutorado em torno dos 30 anos de idade. Esses jovens, com pouco mais de 40 anos, já terão alcançado sua maturidade na capacidade de produção de conhecimento. Mas hoje, os pesquisadores desse nível representam menos de $20 \%$. Os pesquisadores de nível sênior são os mais antigos. E estes estão se aposentando induzidos, nos primeiros anos 90, pela política do Presidente Collor de Mello, depois, a partir de 1995, pelo Governo FHC e, agora, pela aparente continuidade do Governo Lula. Sem estímulo à permanência no magistério superior e sem a reposição de vagas com a abertura de concursos plenos, cria-se um vácuo entre os que saíram e os novos que ainda não alcançaram a maturidade exigida para o desempenho da vida intelectual a que são chamados.

Gráficos resultantes de análises realizadas com o conjunto dos dados da ANDIFES, pelo Fórum de Reitores de Planejamento e Administração, evidenciam as seguintes tendências em nível nacional, no período 1995 a 2000:

- reduziu-se o número de docentes ativos $(-13,5 \%)$,

- reduziu-se o número de mestres (-23,3\%), compensado pelo aumento do número de doutores (31,2\%);

- aumentou o número de bolsas concedidas pela CAPES $(57,8 \%)$, o que sinaliza um investimento público na qualificação de pessoal universitário;

- aumentou o número de vagas oferecidas no vestibular $(26,2 \%)$,

- quase dobrou o número de vagas oferecidas no noturno $(96,8 \%)$,

- aumentou o número de alunos matriculados na graduação (26,3\%) e mais que dobrou na pós-graduação $(154,6 \%)$;

- duplicou-se o número de dissertações de mestrado defendidas (139,3\%),

- quase triplicou-se o número de teses de doutorado (250,4\%), o que indica um aumento de produtividade científica de alunos e de professores e crescimento nos serviços oferecidos à sociedade pelas instituições de ensino superior;

- aumentou o número de docentes aposentados $(22,5 \%)$,

- aumentou o número de concursos públicos para docentes efetivos até 1998 e depois reduziu-se drasticamente (-83,9\%), tendo sido ainda maior a redução, durante todo período para pessoal técnicoadministrativo efetivo $(99,6 \%)$, o que é coerente com a sobrecarga de trabalho docente e a carência de infra-estrutura de apoio para muitas atividades;

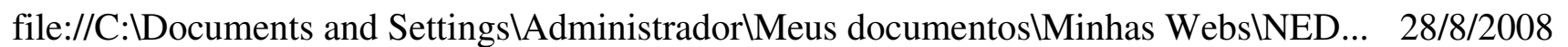


- reduziram-se os recursos para manutenção e capital (OCC), o orçamento com pessoal ativo e com pessoal inativo, o que evidencia a perda de poder aquisitivo dos servidores e outras carências em materiais e de serviços no funcionamento das instituições.[4].

O dia-a-dia departamental evidencia o aumento do número de contratos temporários de docentes e de funcionários, o que sinaliza a terceirização de serviços e a precarização do trabalho docente dos jovens contratados por tempo determinado, sem carga horária para pesquisa, sem vinculação departamental efetiva e sem direito a tempo remunerado para qualificação.

A série histórica de dados de 1995 a 2000 de uma universidade pública, a Universidade Federal Fluminense, à qual pertenço, acompanha os dados para todo Brasil. Mostra que houve, nesse período: um aumento de 108,7\% no número de alunos matriculados na Graduação (de 10.145 em 1995 a 21.177 em 2000); um aumento de 372,7\% na Pós-graduação (de 1.107 em 1995 para 5.223 em 2000, incluindo latu e strictu senso);mas o número de docentes na ativa evoluiu em sentido inverso, reduziu-se em $13,5 \%$ (de 2.965 em 1995 a 2.478 em 2000).

Vê-se, ainda, que a segunda onda de indução à aposentadoria pela ameaça de perda do direito à estabilidade e à aposentadoria dos servidores públicos com salário integral, ocorreu do primeiro para o segundo ano do Governo FHC. Isso se expressa no número de docentes aposentados que cresceu $88,2 \%$ de 1995 para 1996 (passou de 595 para 1.120) e chegou a 108,4\% acumulados de 1995 a 2000 (de 595 em 1995 a 1240 em 2000). [5]

Essa política errática de formar pessoal e restringir as condições de acesso e de exercício dos serviços públicos na educação superior sinaliza o projeto de mercantilização da educação em curso, com o horizonte imprevisível da vigência da internacionalização dos serviços educacionais como quer a OMC (Organização Mundial do Comércio). "A idéia é que os serviços de ensino sejam comercializados livremente, facilitando operações como a atuação de grupos educacionais estrangeiros e a aprovação de cursos à distância, o que pode alterar leis nacionais." [6] É o lado obscuro do processo aberto de privatização do ensino superior que já ostenta a média nacional aproximada de $70 \%$ das matrículas no ensino privado. Ocorre uma inversão dos meios em fins ao se permitir que os fins sociais, que a educação deve ter em qualquer sociedade, se tornem objeto de manipulação ou meios de enriquecimento privativo de outros indivíduos, grupos e países. No caso do Brasil, é o que caracteriza nossa dependência em relação a centros hegemônicos como os Estados Unidos e a Europa. São esses interesses externos que comandam a cultura, a acumulação e a distribuição dos bens culturais entre os quais a educação. Tergiversa-se sobre valores e seus significados na vida de um povo, na consciência de seus educadores. Preconiza-se na escola o modelo empresarial de participação, os parâmetros da qualidade total baseada em critérios de eficiência que distorcem os fins da educação criativa, transformadora, da formação profissional como desenvolvimento humano gerador de cultura [7]

No âmbito do ensino superior, estas reformas, apoiadas em forte vontade política, detalhados instrumentos jurídicos produzidos pelo Executivo e recursos externos, conduziram a um processo de regressão na democratização do conhecimento nas diversas regiões do país. Opera-se o desmonte progressivo da capacidade das instituições e de seus profissionais, de oferecer ensino e desenvolver a 
pesquisa e a extensão dentro dos padrões de qualidade que a sociedade tem o direito de exigir. Sob o signo do mercado e da privatização, compromete-se a formação crítica das novas gerações que devem constituir os quadros mais preparados do país, e reduz-se a possibilidade de um mínimo de soberania propiciada pela produção do conhecimento .

A soberania dos países não advém apenas da posse de armas para defender seu território, mas também da autonomia para produzir conhecimento e responder às demandas de vida de seu povo. Assim, entende-se porque a educação se coloca como uma questão estratégica, no nível básico para a educação fundamental e média de crianças e adolescentes, e no nível superior para o aperfeiçoamento profissional, científico e tecnológico de jovens e adultos. Estes não são elementos autônomos, isolados, mas profundamente imbricados uns em outros, enraizados no tecido social e disseminados pela palavra, pelos discursos que construímos no entendimento e nas ações que viabilizam a vida.

A análise crítica da universidade brasileira, para prestar um serviço ao país, deve apontar as disfunções e os entraves de ordem material e política que prejudicam o desempenho desta instituição, mas também situar estes problemas no âmbito mais amplo de projetos societários alternativos do país e de sua inserção internacional.

Diante das incertezas em relação à garantia de direitos, para quem já cumpriu o tempo de serviço e/ou tempo de contribuição, e diante do que se anuncia sobre a reforma da previdência em curso no país, centenas de professores e pesquisadores buscam a aposentadoria. Esta decisão não trata de assegurar um privilégio, mas de afirmar um direito. Por força de uma oposição combativa e por compromissos éticos e políticos, foi possível resistir à aposenta durante a gestão Collor e o governo FHC. Volta, agora, a pressão do discurso governamental que toma a parte pelo todo, não explicitando todos os dados da questão da previdência, inclusive o uso dos recursos.

Não é nada fácil compreender a posição que está sendo tomada pelo governo, mas sua direção vai se tornando mais evidente: o posicionamento manifesto na Carta de Brasília não apenas chancela a agenda política de reformas previdenciárias construída pelos governos anteriores, expressando uma avaliação positiva de seus resultados, como também reproduz uma visão gerencial e fiscalista na condução da reforma, em detrimento de uma mobilização para a construção de novas possibilidades. (...) Estimativas de evasão e renúncia entre 1997 e 2001 , dão conta de um montante no valor de $R \$ 180$ bilhões, um número impressionante, principalmente se o compararmos com o déficit de mais ou menos $\mathrm{R} \$ 77$ bilhões na conta do Regime Geral de Previdência Social no mesmo período. Neste quadro, torna-se impossível não reconhecer que a afirmação da sustentabilidade do RGPS só pode estar associada à renúncia ao desafio de estabelecer novos parâmetros de gestão pública para o mais importante fundo de provisão social criado pelos trabalhadores brasileiros ao longo dos últimos oitenta anos [8].

Ao nivelar a iniciativa pública com a privada, sinaliza-se um esvaziamento da função pública cujo princípio básico são os serviços oferecidos independentemente do poder de compra de cada brasileiro. Alega-se que a universidade pública é elitista. Elitista, sim, é a sociedade que governa o país há quinhentos anos e sempre restringiu a uma parcela da população o alcance dos serviços sociais básicos, entre os quais a educação em todos os seus níveis. O povo brasileiro necessita de educação de base: letramento ou 
capacidade de ler os sinais escritos e de ler a realidade que lhes dá significado, educação para a convivência no trânsito, para a saúde, a alimentação e tantas coisas mais. Esta é, antes de tudo, uma função pública, promover a elevação das pessoas ao seu nível de dignidade como seres humanos. É nas universidades públicas, nas pós-graduações, principalmente, que sindicalistas, líderes comunitários, agentes sociais de ongs e de movimentos sociais vêm buscar mais formação para atuar com uma compreensão alargada pelo conhecimento que a universidade oferece.

A quem serve esta situação que força o afastamento de tantos profissionais (formados com recursos públicos, no auge de sua produtividade) do espaço público com o conhecido deslocamento para as instituições privadas? O resgate de nossa cidadania como professores e pesquisadores comprometidos com o conhecimento e com a educação pública, que deve servir às novas gerações, exige dos novos governantes a compreensão do papel estratégico dos professores e da produção do conhecimento na consolidação de um processo democrático.

1] Pesquisadora Associada do Programa de Pós-Graduação em Educação - Mestrado e Doutorado, Núcleo de Estudos, Documentação e Dados sobre Trabalho e Educação (Neddate), ex-Professora Titular da Universidade Federal Fluminense. Este texto foi escrito, originalmente, como carta aberta aos colegas professores da UFF, por ocasião de minha recente aposentadoria (abril/2003). mciavatta@terra.com.br [2]Ciavatta, Maria. Universidade, pecado nativo. As práticas educativas de uma universidade privada. Rio de Janeiro: USU, 1982. Relatório de Pesquisa.

[3] Segundo recente artigo da Presidente da SBPC, Profa. Glaci Zancan.Jornal da Ciência, SBPC. 04-042003, p. 9.

[4] . ANDIFES. Indicadores de Desempenho das IFES, 1995-2000. Brasília: ANDIFES - Associação Nacional de Dirigentes das Instituições Federais de Ensino Superior, 2002.

[5] Op. cit.

[6] Strauss, Luiz R. OMC discute novas regras para a educação. Folha de São Paulo, dom., 30-03-2003, p. C1.

[7] FURTADO, Celso. O capitalismo global. Rio de Janeiro: Paz e Terra, 1998.

[8] "As chamadas 'reformas estruturais' monitoradas pelo Banco Mundial e pelo FMI, já atingiram 11 dos 18 países das Américas do Sul e Central (...)". "Países que ainda não foram totalmente reformados: Brasil, Venezuela, Guatemala, Equador, Honduras, Panamá, Paraguai e Peru”. Dados do documento Propostas da CUT para a Previdência Social. CUT Nacional, setembro de 2002”. Andrade, Eli lôla Gurgel. Governo Lula e o Estado de Bem-estar. Teoria e Debate. Revista Trimestral da Fundação Perseu Abramo, vol. 16, no. 33, mar./abr./mai. 2003, p. 21-24.

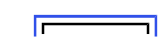

file://C:LDocuments and Settings\AdministradorlMeus documentos\Minhas Webs\NED... 28/8/2008 
volta

file://C:|Documents and Settings\AdministradorlMeus documentos\Minhas Webs\NED... 28/8/2008 